\title{
Effect of circuit training on body composition, physical fitness, and metabolic syndrome risk factors in obese female college students
}

\author{
Ji-Woon Kim, Yeong-Chan Ko, Tae-Beom Seo, Young-Pyo Kim* \\ Department of Kinesiology, College of Natural Science, Jeju National University, Jeju, Korea
}

The purpose of this study was to investigate the effect of a 12-week circuit training program on health-related physical fitness and metabolic syndrome risk factors in obese female college students. Twenty subjects with over $30 \%$ of accumulated body fat voluntarily participated and were randomly allocated to the control group $(n=10)$ or circuit training group $(n=10)$. The circuit training program consisted of 10 types of resistance and aerobic exercise and was performed 3 times per week for 12 weeks. Health-related physical fitness and metabolic syndrome risk factors were analyzed to elucidate the effect of the circuit training. Significant differences between groups were determined with two-way repeated analysis of variance and paired $t$-test. As a result of this study, body weight, \% body fat, and body mass index in the circuit training group was significantly decreased compared to the control group. All health-related physical fitness indicators such as back strength, sit-up, sit-and-reach, and 1,600 m running time showed relative effects between groups or over time. Among the metabolic syndrome risk factors, waist measurement, triglyceride, and total cholesterol were significantly decreased but blood glucose, high-density lipoprotein cholesterol and low-density lipoprotein cholesterol did not show any significant difference. Therefore, the present data suggested that circuit training for 12 weeks may be effective in improving physical fitness and preventing metabolic diseases.

Keywords: Circuit training, Body composition, Physical fitness, Metabolic syndrome, Risk factors, Obese

\section{INTRODUCTION}

Obesity has been known as a medical condition in which excess body fat has accumulated to the extent that it may have a negative effect on health (World Health Organization, 2016). World Health Organization (2016) reported that in $2014,13 \%$ of adults over age 18 (11\% for men and $15 \%$ for women) suffered from obesity and it has increased to more than twice the levels compared to those in 1980. In Korea, the adult population with a body mass index (BMI) of $25 \mathrm{~kg} / \mathrm{m}^{2}$ or more was reported to steadily increase from 2005 to 2013 (Ministry for Health and Welfare, 2017). Previous studies on obesity have emphasized that a persistent increase in the obese population is caused by a decrease in physical activity and excessive intake of nutrition due to the development of industrial technology (Boyland and Whalen, 2015).

Obesity has a high correlation with the decrease of insulin function, the occurrence of various cardiovascular diseases and metabolic syndrome (Matsuda and Shimomura, 2013; Reaven, 2004). Increasing these physiological problems in the obese compared to people with normal weight. For the prevention and treatment of obesity and metabolic syndrome, Schwingshackl et al. (2013) has recommended performing a variety of exercise programs including aerobic exercise, resistance training and flexibility. Recently it has been suggested that the 12-week cycle exercise resulted in a significant reduction in body weight, BMI, and body fat percentage in body composition as well as a decrease in metabolic syndrome risk factors including waist circumference, blood pressure,
${ }^{*}$ Corresponding author: Young-Pyo Kim (iD https://orcid.org/0000-0001-6662-1393 Department of Kinesiology, College of Natural Science, Jeju National University, 102 Jejudaehak-ro, Jeju 63243, Korea

Tel: +82-64-754-3584, Fax: +82-64-757-1752, E-mail: kimyp@jejunu.ac.kr Received: April 3, 2018 / Accepted: May 7, 2018
This is an Open Access article distributed under the terms of the Creative Commons Attribution Non-Commercial License (http://creativecommons.org/licenses/by-nc/4.0/) which permits unrestricted non-commercial use, distribution, and reproduction in any medium, provided the original work is properly cited. 
total cholesterol (TC), high-density lipoprotein cholesterol (HDL-C), and low-density lipoprotein cholesterol (LDL-C) of a middle-aged obese women (Myers et al., 2015).

Components of health related physical fitness include body composition, muscle strength, muscle endurance, flexibility, and cardiopulmonary function. Arena and Cahalin (2014) reported that there were significant correlations between obesity and health-related physical fitness and that obese people with lower cardiopulmonary function had higher cardiovascular risk indexes than those with higher cardiopulmonary function. It has been well documented that regular physical activity not only decreased $\%$ body fat and body weight but also increased health-related physical fitness of middle-aged obese woman (Church et al., 2006).

With these research findings, performing exercise for a certain period of time is absolutely necessary for prevention and treatment of physiological problems in obese people. But almost all previous studies on effect of exercise for obesity have mainly focused on obese middle-aged women, and there are few studies on obese female college students.

Therefore, the purpose of this study was to investigate the effect of 12 -week circuit training program on body composition, physical fitness, and metabolic syndrome risk factors in obese female college students.

\section{MATERIALS AND METHODS}

\section{Participants}

The participants in this study were 20 female college students with obesity, where over $30 \%$ of body fat had accumulated. As

Table 1. The characteristics of the subjects

\begin{tabular}{lcc}
\hline Variable & Exercise group $(\mathrm{n}=10)$ & Control group $(\mathrm{n}=10)$ \\
\hline Age $(\mathrm{yr})$ & $22.90 \pm 2.23$ & $24.50 \pm 1.72$ \\
Height $(\mathrm{cm})$ & $158.65 \pm 5.17$ & $157.58 \pm 3.08$ \\
Weight $(\mathrm{kg})$ & $68.08 \pm 10.65$ & $64.24 \pm 11.84$ \\
Percent body fat $(\%)$ & $38.98 \pm 5.14$ & $35.51 \pm 6.88$ \\
\hline
\end{tabular}

Values are presented as mean \pm standard deviation. shown in Table 1, all voluntary participants were randomly allocated to the control group $(n=10)$ and the circuit training group $(n=10)$. Before beginning the study, participants were informed about study orally and they submitted their written informed consent to researchers. And this research was conducted ethically according to international guidelines.

\section{Circuit training program}

Circuit training is one of the most popular exercise methods to build both muscular strength and endurance. We performed a modified training program, according to a previously described method (Bocalini et al., 2012). As shown in Table 2, the training program consisted of 10 types of resistance and aerobic exercise and was done 3 times per week for 12 weeks. Specifically, the resistance exercise program was comprised of push-up, squat, crunches, lunge and superman exercise and an aerobic exercise program comprised a light jumping, running on the spot, foot stamping, steps, jumping jack.

To set the intensity of circuit training, firstly maximum heart rate (HRmax) was calculated using the equation [206.9(0.67×age)] reported by Gellish (2007) and then the target heart rate was established. In weeks $1-8,50 \%-60 \%$ of HRmax was performed. In weeks 9-12, 60\%-70\% of HRmax was performed. Circuit training was performed for $60 \mathrm{~min}$ including time of warm-up (10 min) and cool-down (10 min). Each exercise in the training program was performed for $30 \mathrm{sec}$, and resting time was 20 sec between each exercise and 3 min between sets.

\section{Fitness measurement}

We measured health-related physical fitness such as body composition, back strength, sit-up, flexibility, and cardiopulmonary function. Body composition was measured by Inbody 720 (Biospace Co., Seoul, Korea) to confirm the height, weight, \% body fat, body fat and lean body mass (LBM) before and after 12 weeks of circuit training. Back strength was measured with a digital back muscle dynamometer (T.K.K. 5402 BACK D, Takei Scientific Instrument Co, Niigata, Japan) and sit-up (T.K.K. 5,505 m,

Table 2. Circuit training program

\begin{tabular}{|c|c|c|c|c|}
\hline Parameter & & Events & Intensity & Time \\
\hline Warm-up & Dynamic stretching & & 40\%-50\% HRmax & $10 \mathrm{~min}$ \\
\hline Circuit training & $\begin{array}{l}\text { Resistance exercise } \\
\text { Aerobic exercise }\end{array}$ & $\begin{array}{l}\text { Push-up, squat, crunches, lunge and superman exercise } \\
\text { A light jumping, running on the spot, foot stamping, steps, jumping jack }\end{array}$ & $\begin{array}{l}\text { In weeks 1-8, 50\%-60\% HRmax } \\
\text { In weeks 9-12,60\%-70\% HRmax }\end{array}$ & $40 \mathrm{~min}$ \\
\hline Cool-down & Static stretching & & 40\%-50\% HRmax & $10 \mathrm{~min}$ \\
\hline
\end{tabular}

HRmax, maximum heart rate. 
Takei Scientific Instrument Co.) was measured for 60 sec. Flexibility was examined using the digital anteflexion meter (T.K.K. 5,111 sit and reach, Takei Scientific Instrument Co.) and cardiopulmonary function was evaluated by $1,600-\mathrm{m}$ record. All measurements were performed twice except 1,600-m running and the highest record was selected.

\section{Blood analysis}

Before and $24 \mathrm{hr}$ after circuit training, $5 \mathrm{~mL}$ of blood was collected from the antecubital vein under fasting conditions ( $>12$ $\mathrm{hr}$ ). The blood samples were centrifuged for $20 \mathrm{~min}$ at 3,600 rpm and stored at $-80^{\circ} \mathrm{C}$ until analysis. Levels of triglyceride (TG), HDL-C, LDL-C, and TC were analyzed using enzymatic colorimetric assay. And fasting glucose concentration was analyzed using enzymatic kinetic assay.

\section{Statistical analysis}

PASW Statistics ver. 18.0 (SPSS Inc., Chicago, IL, USA) was used to determine the effect of 12 -week circuit training. To confirm the main effect, we used a two-way repeated analysis of vari-

Table 3. The result for body composition

\begin{tabular}{llclc}
\hline Variable & Group & Pre & \multicolumn{1}{c}{ Post } & F-value \\
\hline Body weight $(\mathrm{kg})$ & Control & $64.24 \pm 11.84$ & $65.47 \pm 12.82$ & $\mathrm{G} \times \mathrm{P}: 11.954^{*}$ \\
& Exercise & $68.08 \pm 10.65$ & $65.21 \pm 10.91^{*}$ & \\
\% Body fat $(\%)$ & Control & $35.51 \pm 6.88$ & $36.50 \pm 7.10$ & $\mathrm{G} \times \mathrm{P}: 15.110^{*}$ \\
& Exercise & $38.95 \pm 5.14$ & $36.07 \pm 6.73^{*}$ & \\
Lean body mass $(\mathrm{kg})$ & Control & $40.89 \pm 4.64$ & $40.99 \pm 5.00$ & $\mathrm{G} \times \mathrm{P}: 0.088$ \\
& Exercise & $41.24 \pm 5.13$ & $41.23 \pm 4.85$ & \\
\multirow{3}{*}{ Body mass index $\left(\mathrm{kg} / \mathrm{m}^{2}\right)$} & Control & $25.29 \pm 4.97$ & $25.82 \pm 5.33$ & $\mathrm{G} \times \mathrm{P}: 12.182^{*}$ \\
& Exercise & $27.39 \pm 4.06$ & $26.25 \pm 4.25^{*}$ & \\
\hline
\end{tabular}

$G \times P$, group $\times$ period.

${ }^{*} P<0.05$, significantly different from pretest. ${ }^{*} P<0.05$, significantly interaction among group and period.

Table 4. The result for health-related fitness

\begin{tabular}{lllll}
\hline Variable & Group & \multicolumn{1}{c}{ Pre } & \multicolumn{1}{c}{ Post } & F-value \\
\hline Back strength $(\mathrm{kg})$ & Control & $50.30 \pm 13.15$ & $48.20 \pm 12.64$ & $\mathrm{G} \times \mathrm{P}: 26.412^{*}$ \\
& Exercise & $44.65 \pm 11.90$ & $60.17 \pm 15.60^{*}$ & \\
Sit-up & Control & $24.30 \pm 4.90$ & $25.30 \pm 5.12$ & $\mathrm{G} \times \mathrm{P}: 10.799^{*}$ \\
(frequency for 60 sec) & Exercise & $24.10 \pm 6.47$ & $30.40 \pm 4.38^{*}$ & \\
Sit-and-reach (cm) & Control & $14.51 \pm 8.40$ & $13.05 \pm 7.26$ & $\mathrm{G} \times \mathrm{P}: 18.455^{*}$ \\
& Exercise & $17.45 \pm 9.67$ & $20.83 \pm 8.44^{*}$ & \\
1,600-m running time & Control & $686.57 \pm 87.77$ & $725.35 \pm 72.94$ & $\mathrm{G} \times \mathrm{P}: 33.753^{*}$ \\
(sec) & Exercise & $676.56 \pm 64.00$ & $594.69 \pm 81.28^{*}$ & \\
\hline
\end{tabular}

$\mathrm{G} \times \mathrm{P}$, group $\times$ period.

${ }^{*} P<0.05$, significantly different from pretest. ${ }^{*} P<0.05$, significantly interaction among group and period. ance. If there was a significant interaction effect, an independent $t$-test between groups or a paired $t$-test between times was applied. All values are expressed as mean \pm standard deviation. $P<$ 0.05 was considered significant.

\section{RESULTS}

\section{Change in body composition}

Body composition before and after the circuit training program is shown in Table 3. In the circuit training group, body weight $(F=11.954, P<0.05), \%$ body fat $(F=15.110, P<0.05)$, and BMI $(F=12.182, P<0.05)$ were decreased significantly over time and between groups. But LBM $(F=0.088, P=0.968)$ showed no relative effects between groups or over time.

\section{Change in health-related physical fitness}

Health-related physical fitness before and after the circuit training program are shown in Table 4. In the circuit training group, back strength $(F=26.412, P<0.05)$, sit-up $(F=10.799, P<0.05)$, and sit-and-reach $(F=18.455, P<0.05)$ were significantly increased over time and between groups, as well as the 1,600-m re$\operatorname{cord}(F=33.753, P<0.05)$, and all showed relative effects between groups or over time.

\section{Change in metabolic syndrome risk factors}

Metabolic syndrome risk factors before and after circuit training program are shown in Table 5 . In the circuit training group, waist circumference $(F=13.951, P<0.05)$, and TG $(F=8.120, P<0.05)$

Table 5. The result for metabolic syndrome risk factors

\begin{tabular}{llccc}
\hline Variable & Group & Pre & Post & F-value \\
\hline Waist circumference & Control & $77.90 \pm 9.54$ & $78.88 \pm 10.08$ & $\mathrm{G} \times \mathrm{P}: 13.951^{*}$ \\
(cm) & Exercise & $83.80 \pm 8.14$ & $77.33 \pm 8.36^{*}$ & \\
Blood glucose (mg/dL) & Control & $85.90 \pm 6.90$ & $90.40 \pm 8.14$ & $\mathrm{G} \times \mathrm{P}: 0.819$ \\
& Exercise & $94.00 \pm 22.38$ & $91.60 \pm 3.78$ & \\
Triglyceride (TG, mg/dL) & Control & $69.70 \pm 41.90$ & $75.60 \pm 36.62$ & $\mathrm{G} \times \mathrm{P}: 8.120^{*}$ \\
& Exercise & $100.40 \pm 48.08$ & $74.30 \pm 29.87^{*}$ & \\
HDL-C (mg/dL) & Control & $76.20 \pm 12.56$ & $77.60 \pm 11.42$ & $\mathrm{G} \times \mathrm{P}: 0.330$ \\
& Exercise & $68.50 \pm 16.28$ & $67.70 \pm 10.35$ & \\
$\mathrm{LDL}-\mathrm{C}(\mathrm{mg} / \mathrm{dL})$ & Control & $109.60 \pm 31.61$ & $109.10 \pm 26.22$ & $\mathrm{G} \times \mathrm{P}: 0.479$ \\
& Exercise & $111.70 \pm 23.62$ & $106.10 \pm 21.99$ & \\
Total cholesterol & Control & $199.80 \pm 39.16$ & $196.90 \pm 26.24$ & $\mathrm{G} \times \mathrm{P}: 2.180$ \\
(mg/dL) & Exercise & $200.60 \pm 29.26$ & $184.20 \pm 23.24^{*}$ & \\
\hline
\end{tabular}

HDL-C, high-density lipoprotein cholesterol; LDL-C, low-density lipoprotein cholesterol; $\mathrm{G} \times \mathrm{P}$, group $\times$ period.

${ }^{*} P<0.05$, significantly different from pretest. ${ }^{\#} P<0.05$, significantly interaction among group and period. 
were decreased significantly over time and between groups. But blood glucose $(F=0.819, P=0.741)$, HDL-C $(F=0.330, P=0.806)$, and LDL-C ( $F=0.479, P=0.307)$ showed no relative effects between groups or over time. Although TC did not show significant effect between groups, circuit training for 12 weeks significantly decreased TC concentration over time.

\section{DISCUSSION}

Body composition refers to the characteristics of the human body including the body fat, $\%$ body fat, muscle mass, and LBM. With advancing aging, in general, body weight and $\%$ body fat is gradually increased but LBM is decreased (Sziva et al., 2009). These negative alterations of body composition can lead to metabolic syndrome and exercise has been well known as mediator to positively change body composition (Theodorakopoulos et al., 2017).

In this study, circuit training for 12 weeks significantly decreased body weight, $\%$ body fat, and BMI over time and showed relative effect between groups. Most previous studies suggested that aerobic exercise ( 5 times for 12 weeks at $40 \%-70 \%$ maximal oxygen uptake), high intensity combined exercise ( 5 times for 3 weeks) or Pilates exercise (3 times for 8 weeks) could down-regulate body weight, $\%$ body fat, and BMI of obese people when compared to the nonexercise group (Şavkin and Aslan, 2017). Changes in body composition in this study are consistent with many previous studies. However, unlike the above variables of body composition, LBM did not represent a statistical significant difference between group or over time. And this result is different from a number of previous studies in which exercise could significantly increase LBM of obese people (Liao et al., 2018). We think that this difference is due to the different exercise types, time, duration and intensity applied in this experiment. Findings of this study on body composition indicate that regular circuit training for 12 weeks helped obese people improve weight and \% body fat. Circuit training is thus useful for prevention and treatment of obesity.

We confirmed that a 12-week circuit training program significantly improved muscle strength, muscle endurance, flexibility, and cardiopulmonary fitness compared to the nonexercise group. In previous studies on muscle strength and endurance, combined exercise for 12 weeks or high intensity circuit training for 8 weeks increased grip and back strength as well as muscle endurance in middle-aged obese woman (Smith-Ryan et al., 2016). Also Myers et al. (2015) suggested that physical activity increased flexibility and cardiopulmonary fitness of obese woman and that cardiopulmonary endurance was improved in severely obese woman as a result of a swimming exercise program 3 times a week for 12 weeks (Lee and Oh, 2014; Rolland et al., 2004). The enhancement of muscle strength, endurance, and flexibility in this study is due to a gradual increase in exercise intensity and repetition frequency during resistance exercise and cardiopulmonary fitness was improved by continuous aerobic exercise. It is thus considered a relevant exercise to improve health-related physical fitness and the quality of life for obese people.

Obesity is a serious medical condition that can lead to the development of metabolic syndrome such as abdominal obesity, hyperlipidemia, hypertension, diabetes as well as coronary artery disease when left untreated for a long time (Iwashima et al., 2004).

TG, cholesterol, and phospholipids are the important lipids found in the human body, which are transported as complexes of lipid and proteins known as lipoproteins. Lipoprotein is classified as HDL-C, LDL-C, and very-LDL-C. They are critical indicators for prediction of coronary artery disease. Wagmacker et al. (2017) reported that HDL-C and LDL-C were up-regulated and down-regulated in middle-aged woman with over $30 \mathrm{BMI}$, respectively, and resistance and aerobic exercise for 12 weeks positively altered the level of HDL-C, LDL-C and TG in the blood. Regular exercise was effective in the improvement of metabolic syndrome and adult diseases through the regulation of obesity index (Solymoss et al., 2003). However, in the present study, we confirmed no relative effect between groups and over time on TC, HDL-C, and LDL-C concentration as a result of circuit training for 12 weeks. These differences with previous studies are due to the normal range of TC, HDL-C, and LDL-C in obese female college students, unlike those in obese middle-aged woman.

To investigate the effect of circuit training on metabolic syndrome, we investigated 6 factors (waist circumference, blood glucose, TG, HDL-C, LDL-C, and total cholesterol) known as metabolic syndrome risk factors. Among these factors, waist circumference and TG were positively changed after 12-week circuit training. Generally, waist circumference is used as the most effective index to determine abdominal obesity, and TG is the main constituent of body fat in humans (Lean et al., 1995). Abdominal obesity is associated with cardiovascular disease, and visceral fat is known to increase the risk of insulin resistance, hyperlipidemia, hypertension, coronary artery disease, and dyslipidemia (Després et al., 2008). Villareal et al. (2006) suggested that participation in regular exercise could decrease waist circumference and blood TG 
levels in obese people and body pump exercise for 8 weeks showed significant changes in waist circumference in obese female college students (Stensvold et al., 2010). Improvement of waist circumference and TG were seen in the present study. We are convinced that circuit training can help prevent cardiovascular disease and metabolic syndrome in obese people.

Taken together, obesity is a severe medical condition that is able to induce metabolic syndrome and coronary artery disease. And circuit training for 12 weeks decreased body weight, \% body fat, BMI, waist circumference, TG, and leptin as well as increased health-related physical fitness. Therefore our findings provide important evidence that regular circuit training may be regulator to prevent and overcome metabolic syndrome in obese people.

\section{CONFLICT OF INTEREST}

No potential conflict of interest relevant to this article was reported.

\section{ACKNOWLEDGMENTS}

This research was supported by the 2017 scientific promotion program funded by Jeju National University.

\section{REFERENCES}

Arena R, Cahalin LP. Evaluation of cardiorespiratory fitness and respiratory muscle function in the obese population. Prog Cardiovasc Dis 2014;56:457-464.

Bocalini DS, Lima LS, de Andrade S, Madureira A, Rica RL, Dos Santos RN, Serra AJ, Silva JA Jr, Rodriguez D, Figueira A Jr, Pontes FL Jr. Effects of circuit-based exercise programs on the body composition of elderly obese women. Clin Interv Aging 2012;7:551-556.

Boyland EJ, Whalen R. Food advertising to children and its effects on diet: review of recent prevalence and impact data. Pediatr Diabetes 2015;16: 331-337.

Church TS, Kuk JL, Ross R, Priest EL, Biltoft E, Blair SN. Association of cardiorespiratory fitness, body mass index, and waist circumference to nonalcoholic fatty liver disease. Gastroenterology 2006;130:20232030.

Després JP, Lemieux I, Bergeron J, Pibarot P, Mathieu P, Larose E, Rodés-Cabau J, Bertrand OF, Poirier P. Abdominal obesity and the metabolic syndrome: contribution to global cardiometabolic risk. Arterioscler Thromb Vasc Biol 2008;28:1039-1049.

Gellish RL, Goslin BR, Olson RE, McDonald A, Russi GD, Moudgil VK.
Longitudinal modeling of the relationship between age and maximal heart rate. Med Sci Sports Exerc 2007;39:822-829.

Iwashima Y, Katsuya T, Ishikawa K, Ouchi N, Ohishi M, Sugimoto K, Fu Y, Motone M, Yamamoto K, Matsuo A, Ohashi K, Kihara S, Funahashi T, Rakugi H, Matsuzawa Y, Ogihara T. Hypoadiponectinemia is an independent risk factor for hypertension. Hypertension 2004;43:13181323.

Lean ME, Han TS, Morrison CE. Waist circumference as a measure for indicating need for weight management. BMJ 1995;311:158-161.

Lee BA, Oh DJ. The effects of aquatic exercise on body composition, physical fitness, and vascular compliance of obese elementary students. J Exerc Rehabil 2014;10:184-190.

Liao CD, Tsauo JY, Huang SW, Ku JW, Hsiao DJ, Liou TH. Effects of elastic band exercise on lean mass and physical capacity in older women with sarcopenic obesity: a randomized controlled trial. Sci Rep 2018;8:2317.

Matsuda M, Shimomura I. Increased oxidative stress in obesity: implications for metabolic syndrome, diabetes, hypertension, dyslipidemia, atherosclerosis, and cancer. Obes Res Clin Pract 2013;7:e330-341.

Ministry for Health and Welfare. 2008-2016 Local health statistics 2017. Sejong (Korea): Ministry for Health and Welfare; 2017.

Myers J, McAuley P, Lavie CJ, Despres JP, Arena R, Kokkinos P. Physical activity and cardiorespiratory fitness as major markers of cardiovascular risk: their independent and interwoven importance to health status. Prog Cardiovasc Dis 2015;57:306-314.

Reaven G. The metabolic syndrome or the insulin resistance syndrome? Different names, different concepts, and different goals. Endocrinol Metab Clin North Am 2004;33:283-303.

Rolland Y, Lauwers-Cances V, Pahor M, Fillaux J, Grandjean H, Vellas B. Muscle strength in obese elderly women: effect of recreational physical activity in a cross-sectional study. Am J Clin Nutr 2004;79:552-557.

Şavkin R, Aslan UB. The effect of Pilates exercise on body composition in sedentary overweight and obese women. J Sports Med Phys Fitness 2017;57:1464-1470.

Schwingshackl L, Dias S, Strasser B, Hoffmann G. Impact of different training modalities on anthropometric and metabolic characteristics in overweight/obese subjects: a systematic review and network meta-analysis. PLoS One 2013;8:e82853.

Smith-Ryan AE, Trexler ET, Wingfield HL, Blue MN. Effects of high-intensity interval training on cardiometabolic risk factors in overweight/ obese women. J Sports Sci 2016;34:2038-2046.

Solymoss BC, Bourassa MG, Lespérance J, Levesque S, Marcil M, Varga S, Campeau L. Incidence and clinical characteristics of the metabolic syndrome in patients with coronary artery disease. Coron Artery Dis 2003;14:207-212. 
Stensvold D, Tjønna AE, Skaug EA, Aspenes S, Stølen T, Wisløff U, Slørdahl SA. Strength training versus aerobic interval training to modify risk factors of metabolic syndrome. J Appl Physiol (1985) 2010;108: 804-810.

Sziva A, Mészáros Z, Kiss K, Mavroudes M, Ng N, Mészáros J. Longitudinal differences in running endurance and body mass index; a 25-year comparison. Acta Physiol Hung 2009;96:359-368.

Theodorakopoulos C, Jones J, Bannerman E, Greig CA. Effect iveness of nutritional and exercise interventions to improve body composition and muscle strength or function in sarcopenic obese older adults: A systematic review. Nutr Res 2017;43:3-15.

Villareal DT, Miller BV 3rd, Banks M, Fontana L, Sinacore DR, Klein S. Effect of lifestyle intervention on metabolic coronary heart disease risk factors in obese older adults. Am J Clin Nutr 2006;84:1317-1323.

Wagmacker DS, Petto J, Fraga AS, Matias JB, Mota SK, Rodrigues LE, Ladeia AM. Metabolic Reponses to a physical exercise session in women with excess body mass: randomized clinical trial. Lipids Health Dis 2017;16:249.

World Health Organization. Fact Sheet. Obesity and overweight. Geneva (Switzerland): World Health Organization; 2016. 